non-psychotic psychogenic disorders, and catatonic states without stupor such as catatonic excitement.

The mean age of the 11 patients was 38.6 years (range 22-63 years). Duration of illness was 11.7 years (range 0.4-23 years). Diseases were classified according to DSM-III-R criteria (American Psychiatric Association, 1987) as paranoid type of schizophrenia, chronic with acute exacerbation (295.34, $n=7)$, subchronic with acute exacerbation (295.33, $n=1)$, initial manifestation of schizophrenia $(295.30, n=2)$ and schizoaffective disorder $(295.70, n=1)$. The therapeutic effect was measured by means of a rating scale designed by the authors - score 4, extremely severe; score 1 , no catatonic symptoms. Further details of this rating scale will be published elsewhere.

Ten patients with catatonic stupor improved within $60 \mathrm{~min}$ after i.v. biperidene (mean $17.7 \mathrm{~min}$ range $445 \mathrm{~min}$ ). Doses of biperidene were $5 \mathrm{mg}$ in eight patients and $10 \mathrm{mg}$ in two patients. One patient did not improve within 90 min following $15 \mathrm{mg}$ of biperidene and was therefore treated with a 3-day infusion of haloperidol $(60 \mathrm{mg} /$ day $)$, without success. Following renewed biperidene injection catatonic stupor in these patients disappeared within $33 \mathrm{~min}$.

We assume that the evident efficacy of biperidene on stuporous catatonic states is caused by its anticholinergic activity in the basal ganglia. Biperidene binds competitively with acetylcholine to cholinergic muscarinic receptors in the corpus striatum and hippocampus (Larson et al, 1991). Spontaneous, reactive or pharmacologically induced states of immobilisation and/or catalepsy in various animals can be removed by biperidene (Stille \& Sayers, 1975).

Intravenous application of 5 to $15 \mathrm{mg}$ biperidene improves the efficacy and safety of pharmacotherapy in catatonic states. Anticholinergic side-effects of biperidene have proved to be tolerable. No delirious states or anticholinergic sideeffects were observed. However, these promising first results must be confirmed in a controlled study.

American Psychiatric Association (1987) Diagnostic and Statistical Mamual of Mental Disorders (3rd edn revised) (DSM-IIIR). Washington DC: APA

HirschBliR(i, E. (1964) Zur Frage psychischer Wirkungsqualitäten des Akinetons im Rahmen neuroleptischer Pharmakotherapie. Nervenurzt, 9, 419.

Larson, E. W.. Pfennig, M. A. \& Richelson. E. (1991) Selectivity of antimuscarinic compounds for muscarinic receptors of human brain and heart. Psychopharmacology. 103, 62-165.

SAlAM, S. A. \& KILZIEH, N. (1988) Lorazepam treatment of psychogenic catatonia: An update. Journal of Clinical Psychiatry. 49, 1621.
StIlle, G. \& SAYERS, A. (1975) Die Immobilisationsreaktion der Ratte als tierexperimentelles Modell für die Katatonie. Pharmacopsychiatry. 8, 105-114.

Winter, E. \& Grosse, R. (1979) Zur Wirkung von Biperiden bei akuten substuporös-stuporösen Zuständen. Pharmacopsychiatry. 5, 383-387.

Centre for Psychiatry

The Independent Psychopathology Unit

Justus-Liebig-University School of Medicine

35392 Giessen, Germany

\section{Debt and deliberate self-harm}

SIR: Hatcher (BJP, January 1994, 164, 111-114) found it difficult to draw firm conclusions about the rate of debt in the study of deliberate self-poisoning population without a comparative control group. This problem has limited the majority of studies of deliberate self-harm (DSH). I conducted a pilot study to try to deal with this. The control population chosen was from a fracture clinic, the attenders at which, like the DSH population, have established current contact with the hospital service via the casualty department. They were given the same single-page questionnaire as the DSH patients. This consisted of 15 forced choice questions gathering demographic variables and information about employment, debt and psychiatric history. A Hospital Anxiety and Depression Scale (HADS) was incorporated.

To ensure similar sociodemographic characteristics the two groups were stratified into two age groups, two social class groups and by sex, giving equal numbers from both in each strata. This allowed 53 questionnaires from both DSH and control groups to be compared. Sixty-two per cent of each were male, $68 \%$ were less than 35 years old and $19 \%$ were from social class I, II or III.

One question was "Have you had significant worries with debt that you cannot repay?" Ninetysix per cent of the DSH group and $98 \%$ of the control group answered this. Thirty seven per cent of the DSH group replied "yes" compared with $13 \%$ of the control group. This is comparable with the $37 \%$ of self-poisoners in debt reported by Hatcher, as are the median ages of 26 years and 28 years respectively for the debt and non-debt groups. Both these groups had a median age of 31 years in the control group.

In the DSH group however there was no difference in proportion of those who reached 'caseness' for depression (Hamer et al, 1991) between the debt 
and non-debt group (37\% and $44 \%$ respectively, $\chi^{2}=0.03$, d.f. $=1$, NS). The comparable proportions for the control group were $43 \%$ and $2 \%$ (Fisher exact, $P=0.006$ ).

This absence of a difference in depression between those in and not in debt in the DSH group is at variance with the Hatcher's report. Methodological differences, a difference in the proportion of males, the inclusion of those other than selfpoisoners and bias introduced by nursing staff who did not give questionnaires to all DSH patients may explain this. The similarities in ages and the proportions in debt are however striking.

This study found that a brief questionnaire was acceptable for both DSH and this control group. The proportion of questions answered about debt was high and was representative of the other questions. This method may enable large control groups to be studied. In addition this study supports the hypothesis that debt is more common in the DSH population. To draw further conclusions from these numbers is hazardous although the comparative levels of depression associated with debt in both DSH and control populations warrants further investigation.

HAMER, D., SANJeEv, D., Butterworth, E., et al (1991) Using the Hospital Anxiety and Depression Scale to screen for psychiatric disorders in people presenting with deliberate self-harm. British Journal of Psychiatry, 158, 782-784.

\section{Chesterfield Royal Hospital Chesterfield S44 SBL}

SMMON J. TAYLOR

\section{Risk of HIV for women who inject drugs}

SIR: Gossop et al (BJP, January 1994, 164, 101104) suggest that women may be at higher risk of relapse to drug use than men because of their closer social attachment to other drug users. Preliminary results from our survey of opiate users presenting for treatment in south London are broadly in line with those of Gossop et al. However, we found that women who inject drugs may also be at greater risk of HIV infection than men.

Women comprised $24 \%$ of a sample of 97 opiatedependent drug users questioned about sexual and injecting behaviours. They were more likely to be living with a drug user (61\% compared with $31 \%$ of men; $\left.\chi^{2}=6.6, P<0.05\right)$ and to have a sexual partner who was an injecting drug user $(70 \%$ compared with $22 \%$ of men; $\left.\chi^{2}=18.2, P<0.0001\right)$. There were no significant differences between the proportions of men and women who had recently injected drugs, but women were more likely to have injected themselves with equipment that had been used by someone else ( $30 \%$ of women compared with $11 \%$ of men; $\left.\chi^{2}=5.2, P<0.05\right)$. For both sexes, the majority of equipment sharing episodes involved their regular sexual partner, with whom condoms were used by only $20 \%$ of male and $25 \%$ of female clients.

In drug-using couples, women may have less opportunity to negotiate safer sexual and injecting practices, because men play a more active role in procuring drugs and injecting equipment (Klee, 1993). This particular aspect of relationships between male and female drug users has implications for HIV prevention strategies.

KLEE, H. (1993) HIV risks for women drug injectors: heroin and amphetamine users compared. Addiction, 88, 1055-1062.

SAlly PORTER

JAMES ELANDER

SuE STEPHENS

ANDREW JOHNS

JAMES EDEH

Division of Psychiatry of Addictive Behaviour

St George's Hospital Medical School

London SWI7 ORE

\section{Dysphagia in the neuroleptic malignant syndrome}

SIR: The neuroleptic malignant syndrome (NMS) is a recognised complication of psychotropic drug use with a variable outcome (Bristow, 1993). We describe two cases where dysphagia with loss of a gag reflex was a major presenting feature.

Case 1: A 25-year-old male presented acutely psychotic and received zuclopenthixol, chlorpromazine and droperidol. He developed NMS with dysphagia, loss of a gag reflex followed by right lower zone pneumonia which required ventilation for 7 days, during which time he received dantrolene, bromocriptine and lorazepam (Gratz et al, 1992). His fever finally settled on imipenem. No organisms were grown. He was noted to have absent bowel sounds which returned after 9 days following the administration of cisapride. However his swallowing was unaffected by this and returned on day 25. An MRI scan of the brain during the dysphagia showed no evidence of brainstem damage.

Case 2: A 32-year-old male presented with dysphagia and fever and was noted to have a poor gag reflex. He had been receiving chlorpromazine and flupenthixol for 7 weeks. A diagnosis of NMS was made and he received dantrolene, bromocriptine and lorazepam. He developed signs of right lower zone pneumonia which responded to ciprofloxacin and erythromycin. By day 11 he could speak but still was unable to swallow; MRI scanning showed no brainstem abnormalities. He required a tracheostomy and feeding gastrostomy. He had a fatal cardiorespiratory arrest on day 16 due to bilateral pulmonary emboli. 